\title{
ENTRE O ELOGIO E A SUSPEITA: CONSIDERAÇÕES SOBRE O ILUMINISMO EM FOUCAULT E KANT
}

\author{
Rafael Nogueira Furtado ${ }^{1}$ \\ Pontifícia Universidade Católica de São Paulo (PUCSP)
}

\begin{abstract}
RESUMO
O artigo busca evidenciar os pontos de contato entre as análises de Foucault e Kant sobre o Iluminismo. Ademais, cumpre explicitar a relação ambivalente da filosofia contemporânea com a razão esclarecida, ora considerada responsável por práticas de dominação, ora como condição de possibilidade para a autonomia e liberdade. Partindo da declaração de Foucault sobre seu trabalho situar-se na tradição crítica kantiana, trata-se de compreender como os dois filósofos problematizaram o processo de saída do homem de sua menoridade.
\end{abstract}

PALAVRAS-CHAVE: Iluminismo; Razão; Foucault; Kant.

\section{BETWEEN PRAISE AND SUSPICION: CONSIDERATIONS ON ENLIGHTENMENT IN FOUCAULT AND KANT}

\begin{abstract}
:
This paper aims to show the relationships between Foucault's and Kant's analyses on Enlightenment. Moreover, this study tries to reveal contemporary philosophy's ambivalent relation with reason, regarded, on the one hand, responsible for practices of domination, on the other hand, as the foundation of autonomy and liberty. Considering Foucault's claim, according to which his work should be placed in Kantian critic tradition, it intends to comprehend how both philosophers problematize men's emergence from minority.
\end{abstract}

KEYWORDS: Enlightenment; Reason; Foucault; Kant.

\footnotetext{
${ }^{1}$ Mestre em Filosofia e doutorando em Psicologia Social pela Pontifícia Universidade Católica de São Paulo (PUC/SP), São Paulo - Brasil. E-mail: rnfurtado@ yahoo.com.br
} 


\section{Introdução}

Durante o século XVIII, a Europa seria agitada por insurreições intelectuais e políticas, conhecidas como o movimento filosófico do Iluminismo. Este movimento caracterizava-se como a cruzada empreendida pela razão, contra as sombras do dogmatismo e do obscurantismo. As diversas correntes filosóficas subsequentes a este período tornar-se-iam herdeiras destas Luzes.

Michel Foucault, que dedicou seu trabalho à crítica dos dispositivos de controle das sociedades modernas, não se furtou a refletir sobre esta herança. Desde a publicação de História da loucura, pode-se encontrar em seus escritos referências ao Iluminismo. Todavia, o tema passará das margens de seus textos ao centro de suas preocupações, apenas no final da década de 1970. Responsável por esta virada será o estudo do filósofo sobre o opúsculo kantiano Was ist Aufklärung?

Kant (2008) compreende as Luzes como o momento de saída da humanidade de sua menoridade, pela qual ela mesma seria culpada. Uma saída que se concretizaria quando o homem fizesse uso de seu próprio entendimento, sem a direção de outros. Foucault (2011; 2008b; 1990) retoma estas palavras e afirma possuírem uma estreita ligação com seu pensamento.

No ano de 1984, ao assinar um verbete para o Dicionário dos filósofos de Denis Huisman, Maurice Florence (2001, p. 234, grifo do autor), pseudônimo de Foucault, afirma que se ele "está inscrito na tradição filosófica, é certamente na tradição crítica de Kant, e seria possível nomear sua obra História crítica do pensamento". Kant teria explicitado a tensão entre autoridade e autonomia que o filósofo francês tematizou ao longo de seu trabalho. Ele veria no uso esclarecido e livre da razão a superação da menoridade, problematizada por Foucault ao realizar a crítica dos mecanismos modernos de dominação.

A relação entre Foucault e as Luzes, entretanto, não deve ser entendida como continuidade do projeto kantiano. Mais que um conjunto de doutrinas e sistemas de pensamento, o Iluminismo corresponde para ele a uma atitude, uma forma de interrogar a atualidade. Esta atitude permite lançar sobre os acontecimentos históricos o olhar de suspeita, que faz ver no limite de práticas e saberes estabelecidos, sua superação.

\section{Foucault e os diferentes sentidos de lluminismo}

São sumárias, de caráter apenas ilustrativo, as preocupações de Foucault com o Iluminismo, anteriormente ao ano de 1978. Em "A psicologia de 1850 a 1950", texto de 1957, o filósofo associa as Luzes à pretensão das ciências em determinar as leis gerais dos fenômenos da natureza. A psicologia influenciada pelo pensamento esclarecido visaria 
atingir o rigor e objetividade de que gozam estes saberes (FOUCAULT, 1999a). Referência que apareceria novamente em 1961.

Em História da loucura, semelhante caracterização pode ser identificada. O Iluminismo consistirá neste momento histórico, em que se buscará por um conhecimento positivista e racionalmente fundamentado, levando à crescente dominação dos sujeitos. (FOUCAULT, 2005). As Luzes colocar-se-ão aqui em oposição, mas estreitamente relacionadas, à obscuridade da desrazão.

Posteriormente, em 1966, como atenta-nos Kraemer (2011), o posicionamento de Foucault sofrerá uma sutil modificação. Deste ano data o escrito intitulado "Une histoire restée muette", cuja discussão trata do livro A filosofia do Iluminismo (1932) de Ernst Cassirer. Conforme Foucault, nós modernos seríamos tributários de uma herança neokantiana, a qual dividiria a filosofia contemporânea em duas principais vertentes: a helênica, isto é, aquela que busca pelo ser, representada por autores como Hölderlin e Heidegger; bem como a vertente da Aufklärung, que procura determinar os limites de nosso saber (FOUCAULT, 2001).

De acordo com Kraemer (2011, p. 262), "o princípio de deslocamento" do pensamento de Foucault, no tocante à análise das Luzes, está no fato de o filósofo, ao mesmo tempo, reconhecer em Cassirer um Aufklärer e considerar o método de análise histórica deste último como notadamente semelhante à sua arqueologia. Neste texto de 1966, Foucault também identifica no Iluminismo uma preocupação com o presente, o que faria eco com seu próprio trabalho. Isto indicaria, portanto, "uma primeira aproximação de Foucault com a Aukflärung, dissociada do positivismo" (KRAEMER, p. 264).

Esta aproximação não estará consolidada até, porém, a década de 1980. Em 1975, quando da publicação de Vigiar e Punir, Foucault se esforçará para mostrar como, sob o aparente humanismo e liberdade conquistados pelo pensamento esclarecido, encontram-se práticas disciplinares e de controle. A Aukflärung que denuncia as atrocidades do suplício é também aquela que sofistica as formas de assujeitamento. $\mathrm{Na}$ célebre passagem do livro, constata-se que "as 'Luzes' que descobriram as liberdades inventaram também as disciplinas" (FOUCAULT, 2002, p. 183).

Foucault retornará ao problema em 1978, quando da realização de uma mesa-redonda com historiadores, a respeito da temática das prisões, do trabalho historiográfico e da prática filosófica. A partir deste debate, o filósofo produzirá o posfácio do livro L'impossible prison, de Michelle Perrot, publicado em 1980. Nele, em consonância às declarações de 1966, Foucault uma vez mais destaca a influência da Aufklärung sobre o pensamento europeu moderno.

Desta vez, cita os textos de Kant e Mendelssohn sobre o tema. Utilizando-se das palavras de Georges Canguilhem, Foucault (2010b, p. 354) considera as Luzes como "nosso mais "atual passado"” e lança, no 
referido posfácio, um desafio: "por que não começar uma grande inquirição histórica sobre a maneira como a Aufklärung foi percebida, pensada, vivida, imaginada, conjurada, anatemizada, reativada na Europa dos séculos XIX e XX?".

No mesmo ano de 1978, agora no prefácio da edição americana de $O$ normal e o patológico de Canguilhem, o Iluminismo será definido como forma de indagação sobre o presente, e o opúsculo kantiano considerado o texto base para seu entendimento. Dirá Foucault (2008a, p. 354), "dessa questão pela qual a filosofia fez, de sua forma presente e de sua ligação com seu contexto, uma interrogação essencial, pode-se tomar como símbolo o debate associado à Berlinische Monatsschrift e que tinha por tema: Was ist Aufklärung?".

O aparecimento da Aufklärung neste prefácio advém da análise realizada por Foucault sobre os destinos assumidos pela filosofia francesa desde o século XIX. Operando uma vez mais uma divisão esquemática, para ele, duas correntes de pensamento balizariam a diversidade teórica que a França viu surgir nos últimos duzentos anos. A primeira compreenderia a filosofia da experiência de Sartre e Merleau-Ponty; a segunda, a filosofia do conceito e do saber de Cavaillès, Bachelard, Koyré e Canguilhem (FOUCAULT, 2008a).

Esta última corrente de pensamento, a princípio tida como de cunho bastante especulativo, teórico e dissociada da prática política, foi, no entanto, aquela que demonstrou ser mais combativa e inquieta quanto aos efeitos de poder relacionados às formas de saber. Conforme Foucault (2008a), esta aderência e tensão com o presente justificar-se-ia dado seu enraizamento na filosofia da Aufklärung, questionando, como ela, a historicidade e atualidade do pensamento. Desde então, a história teria ganhado dignidade filosófica, de maneira que a filosofia, após a Aufklärung, jamais poderia evitar ou esquivar-se dos problemas que o presente lhe impõe (FOUCAULT, 2008a).

Contemporâneo ao escrito "A vida: a experiência e a ciência", a conferência "Qu'est-ce que la critique?", proferida em 1978, sustenta semelhante argumentação. Nela trata-se de elevar o Iluminismo a acontecimento histórico do qual a filosofia subsequente não poderia se dissociar. Tanto no prefácio de $O$ normal $e$ o patológico, quanto na conferência citada, Foucault atenta-nos para o modo como, entretanto, o problema desdobrou-se diferentemente na França e na Alemanha.

De Hegel, à Escola de Frankfurt, de Nietzsche a Max Weber, será no interior de uma reflexão política e histórica que a Aufklärung, como questão filosófica, se estabelecerá (FOUCAULT, 2008a). No tocante ao pensamento francês, é com Comte, Saint-Simon e os historiadores da ciência, em virtude de um beligerante debate sobre a construção do conhecimento científico, que a Aufklärung encontra sua entrada no século XIX (FOUCAULT, 2008a). 
Ressalta Foucault, porém, que a questão das Luzes se desenvolveria de modo bastante tímido na França, quando comparado à Alemanha. Seria apenas com o aparecimento da fenomenologia e das teorias sobre as estruturas de formação do sentido que este quadro se modificaria (FOUCAULT, 1990).

Ao longo do século XX, a Aufklärung esteve igualmente associada a calorosos debates. Sua memória, na forma de um problema sempre presente, será trazida ao centro de discussões que lhe interrogam sobre eventuais abusos de poder e saber dos quais sua apologia à razão teria sido responsável (FOUCAULT, 2008a). O racionalismo científico do último século, portador recente das esperanças de emancipação antes devotadas à Revolução Francesa do século XVIII, junto a uma crescente preocupação com o despotismo inerente à racionalidade, levarão a suspeitas contra a Aufklärung.

Entretanto, ainda que Foucault evidencie-nos o modo com que ela tornou-se objeto de sensível desconfiança, seus escritos a partir de 1978 revelam uma notável mudança no seu posicionamento. Isto significa que as Luzes não mais serão vistas por ele, como vinculadas ao simples empreendimento de dominação, colocado em movimento no Ocidente moderno. Tampouco indicativas apenas de um projeto autoritário e positivista para o saber. Igualmente não se tratará, para Foucault (2010b), de decidir-se a favor ou contra o Iluminismo, mas reconhecer nele certa atitude, à qual não se poderá ser indiferente.

O que textos deste período de virada revelam-nos é a associação explícita de Foucault à forma de pensamento que ele identifica no movimento esclarecido, sugerindo dever seu trabalho ser compreendido a partir desta vinculação (FOUCAULT, 2011). As análises de Foucault sobre as Luzes, a partir do final dos anos 1970, terão como suporte principal o texto kantiano "Was ist Aufklärung?", de 1784.

\section{Kant e a questão "O que é a Aufklärung?"}

A circunstância de publicação deste texto consiste no debate realizado nas páginas do periódico Berlinischen Monatsschrift, com vistas a esclarecer os leitores sobre o significado e implicações do fenômeno da Aufklärung. Neste debate questionar-se-á o caráter e "idoneidade moral" (TORRES FILHO, 1983) do movimento esclarecido. Seriam as Luzes um perigo para o povo ou para as instituições em que nossa sociedade se apoia? Dúvidas que teriam como gatilho o problema do casamento, tal como colocado por Johann Erich Biester (TORRES FILHO, 1983).

Este membro fundador do periódico publicara certo artigo, no qual sustentava que não mais fosse dado aos eclesiásticos o trabalho de realizar os matrimônios. A estas declarações o pároco Johann Friedrich Zöllner responde em oposição. Argumenta que o casamento, sendo ele responsável 
pela felicidade humana, não deverá estar em igual posição a outras questões legais (TORRES FILHO, 1983).

Em tom de advertência, Zöllner ressalta que a Aufklärung poderia comprometer, se levada a cabo sem crítica, suas próprias conquistas, conduzindo assim à desordem. Por isso, o pároco colocará a questão: o que é a Aufklärung? Questão que "deveria certamente ser respondida antes que se comece a ilustrar!" (TORRES FILHO, 1983, p. 104). Em resposta a Zöllner, Kant (2008, p. 100) publicará no Mensário um artigo ${ }^{2}$, em que define ser a Aufklärung

a saída do homem de sua menoridade, da qual ele próprio é culpado. A menoridade é a incapacidade de fazer uso de seu entendimento sem a direção de outro indivíduo. O homem é o próprio culpado dessa menoridade se a causa dela não se encontra na falta de entendimento, mas na falta de decisão e coragem de servir-se de si mesmo sem a direção de outrem. Sapere aude! Tem coragem de fazer uso de teu próprio entendimento, tal é o lema do esclarecimento.

Conforme Kant (2008, p. 100), esta menoridade seria "cômoda", resultado não de uma condição a que o homem estaria preso por natureza, mas do estado em que se encontra sua vontade. Ser-lhe-ia preferível, por "preguiça" e "covardia" (KANT, 2008, p. 100), transferir a outros o encargo e tutela de si.

E o autor cita três situações que exemplificam a subjugação a esta tutela: o homem não precisa responsabilizar-se por si mesmo, uma vez substitua seu próprio entendimento por um livro que lhe diga como pensar; ou ainda substitua sua consciência por um diretor espiritual; ou mesmo o cuidado com sua própria dieta por um médico que dela se encarregue (KANT, 2008).

"Que, porém, um público se esclareça [aufkläre] a si mesmo é perfeitamente possível", contrapõe Kant (2008, p. 102). Algo que só pode ser atingido de maneira lenta. Ainda que a realização de uma revolução derrube um governo tirânico, esta não será capaz de operar a transformação requerida dos espíritos. Não obstante, bastará liberdade para que o esclarecimento se concretize. Liberdade, para Kant (2008, p. 104, grifo do autor), de "fazer um uso público de sua razão em todas as questões".

\footnotetext{
${ }^{2}$ A resposta de Kant à pergunta do periódico, o que é a Aufklärung?, é simultânea àquela oferecida por Moses Mendelssohn, o qual também procura atender ao problema colocado por Zöllner. Kant, todavia, declara ter finalizado a redação de seu artigo antes que lhe chegasse às mãos o escrito de Mendelssohn. Não mais podendo evitar a publicação de seu texto, o filósofo diz apenas aguardar e observar "até que ponto o acaso terá feito coincidirem os pensamentos". Cf.: KANT, Immanuel. Resposta à pergunta: que é o iluminismo? In: . A paz perpétua e outros opúsculos. Tradução: Artur Morão. Lisboa: Edições 70, 2008, p. 116.
} 
Enquanto os oficiais, os financistas, os sacerdotes dirão "exercitaivos!”, “pagai!”, “creem!”, mas não raciocineis, haverá, todavia, aquele que dirá, ao contrário, "raciocinai, tanto quanto quiserdes, e sobre o que quiserdes, mas obedecei!" (KANT, 2008, p. 104, grifo do autor). Este homem é, segundo Kant, o déspota esclarecido, governante do Estado fundado sobre o princípio da autonomia da razão. Assim, o Iluminismo exige que o uso público da razão seja total e irrestrito. Por outro lado, seu uso privado pode "muitas vezes ser muito estreitamente limitado, sem contudo por isso impedir notavelmente o progresso do esclarecimento" (KANT, 2008, p. 104).

Conforme definição kantiana, denomina-se público o uso da razão no qual o sujeito dirige-se ao "grande público do mundo letrado", enquanto seu uso privado designa aquele realizado "em um certo cargo público ou função a ele confiado" (KANT, 2008, p. 104, grifo do autor). Na circunstância deste uso privado, adverte o filósofo, cabe ao homem obedecer. Em contrapartida, ao exercer seu papel de cidadão, membro de uma comunidade universal de seres racionais, é legítimo que raciocine.

Kant (2008) toma como exemplo dos usos da razão o serviço militar, o pagamento de impostos e o trabalho eclesiástico. Se não é correto que um oficial questione as ordens a que está submetido no exercício de sua função, por outro, é aceitável que raciocine sobre o serviço prestado, e exponha publicamente suas ponderações. Do mesmo modo, deverá o cidadão pagar seus impostos. Porém, é direito seu discutir livremente, dirigindo-se a determinado público, sobre a natureza desta cobrança. Semelhante avaliação pode-se fazer sobre o sacerdote, o qual, ao passo que necessita cumprir, em aquiescência, os rituais do credo de sua escolha, deve ter-lhe garantida a liberdade de professar opiniões contrárias, se julgar preciso.

A obediência coloca-se assim, para o autor, como condição do exercício racional da liberdade e autonomia, de maneira que, se no âmbito privado o sujeito submete-se a uma figura de autoridade, "no uso da razão pública não há obediência a qualquer razão, mas à razão universal" (TEMPLE, 2009, p. 232).

Pelo bem do argumento, Kant (2008, p. 108) leva-nos a indagar sobre a possibilidade de uma função estar de certo modo estruturada em seu exercício privado que, por efeito de "supertutela", impedisse aos sujeitos sua crítica pública. Dirá o filósofo ser isto impossível. "Tal contrato que decidiria afastar para sempre todo ulterior esclarecimento do gênero humano, é simplesmente nulo e sem validade" (KANT, 2008, p. 108). Impedir ou colocar obstáculos para a consecução da Aufklärung "seria um crime contra a natureza humana, cuja determinação original consiste precisamente neste avanço" (KANT, 2008, p. 110).

Para o filósofo, isto também se aplica às leis constituídas. Estas leis devem ser de tal modo que se considere que o próprio povo as estabeleceu, bem como devem permitir ao povo modificá-las, se assim considerar 
necessário. A marcha na direção do esclarecimento é contínua e progressiva, e a constituição escrita dos homens necessita se orientar por ela. Com isto, Kant reconhecerá no Iluminismo não apenas um fato da natureza humana, mas um dever a ser observado. Tornam-se ilegítimas as ações daquele que procura renunciar às Luzes, agindo por meio da censura ou coação.

Expostos estes princípios gerais, o filósofo então se questiona: "vivemos agora em uma época esclarecida?" (KANT, 2008, p. 112, grifo do autor). Sua resposta é negativa. Restaria muito ainda para ser feito, até que o gênero humano saísse de seu estado de menoridade. Entretanto, haveria "indícios" de que para os homens "foi aberto o campo no qual podem lançar-se livremente a trabalhar e tornarem progressivamente menores os obstáculos ao esclarecimento geral" (KANT, 2008, p. 112).

E a época propícia às Luzes, arremata o autor, é esta, "o século de Frederico" (KANT, 2008, p. 112, grifo do autor). Frederico porta a gloriosa insígnia de um esclarecido, tendo contribuído para a emancipação dos homens, ao deixar a critério da consciência moral de cada sujeito os costumes religiosos a serem adotados. Com isto, os homens contariam apenas com sua própria razão como legisladora no campo da moralidade.

Ora, se Kant toma como sinais do esclarecimento questões de ordem religiosa, explica o filósofo, é porque os líderes políticos não teriam nenhum interesse em tutelarem sobre temas como as artes e as ciências. Ademais, não haveria menoridade "mais desonrosa" (KANT, 2008, p. 114) que aquela no campo da religiosidade, relacionado ao âmbito ético e moral.

No mais, detentor de um exército forte, numeroso e disciplinado, Frederico trataria o povo segundo sua própria "dignidade", o qual a natureza dotou do "germe", da "tendência" ao progresso e à liberdade de pensamento (KANT, 2008, p. 114). Poderá o governante então declarar: "raciocinai tanto quanto quiserdes e sobre qualquer coisa que quiserdes; apenas obedecei!"' (KANT, 2008, p. 114, grifo do autor).

Como ressalta Torres Filho (1983), Kant seria capaz, com isto, de responder a Zöllner, e o faria dizendo: o esclarecimento não compromete a ordem civil, dado que este se concretizará apenas quando em estreita consonância a ela.

\section{Aproximações entre Foucault e Kant}

Vemos como as reflexões kantianas sobre a Aufklärung situam-na no intercruzamento das noções de liberdade, autonomia, progresso e obediência. $\mathrm{O}$ filósofo a entende como gesto de coragem expresso por uma divisa, um lema que representa a tarefa imposta a si pela humanidade, de saída de seu estado de menoridade. Sapere aude! Eis a palavra de ordem das Luzes

Neste sentido, importa efetuar a passagem de um estado de heteronomia e subordinação moral, ao uso não tutelado e autônomo do 
entendimento. Para isto, requer-se nada mais que a liberdade de exercer o uso público da razão. Liberdade e autonomia, contudo, não se dissociam da obediência. Ao contrário, elas a requerem, ao menos enquanto obediência à razão universal.

Por sua vez, o estudo de Foucault sobre o texto Was ist Aufklärung? corresponde à tentativa do filósofo de vincular seu trabalho a certa experiência intelectual. Como Kant, ele defende o uso crítico do entendimento e a problematização de formas de autoridade. Porém, recusa a ideia de obediência aos denominados princípios universais e necessários da razão.

Esta recusa não o impede de se considerar herdeiro do esclarecimento. Foucault afirma que a Aufklärung consistiria menos em um sistema de doutrinas que uma atitude diante da atualidade, capaz de colocarlhe questões como: "o que somos nesse tempo que é o nosso", "o que somos hoje"; "o que é nossa atualidade, o que se passa ao nosso redor, o que é nosso presente" (FOUCAULT, 2004, p. 301; 2010a, p. 226). Interrogações que procuram modificar a "relação preexistente entre a vontade, a autoridade e o uso da razão" (FOUCAULT, 2008c, p. 337).

Pode-se dizer que o esforço de Foucault em realizar uma arqueologia dos discursos modernos e uma genealogia dos dispositivos de poder a eles associados, implica em modos de questionar o presente. São exemplos desta prática filosófica seus estudos sobre: o tratamento dado pela psiquiatria à loucura; o surgimento das ciências humanas; as práticas modernas de vigilância e punição; bem como a maneira com que os sujeitos foram levados a fazer uma hermenêutica de seus desejos.

Não obstante, Kant introduz em sua análise outro elemento ausente em Foucault. Se a coincidência entre liberdade e obediência possibilita a emancipação, requer-se para isto um fator que opere esta sobreposição. O filósofo alemão propõe um contrato, certo acordo que selará e assegurará o arranjo político em que se sustentam as Luzes. Acordo que pode ser entendido como "contrato do despotismo racional com a livre razão" (FOUCAULT, 2008c, p. 340), e que tem em Frederico II sua personificação.

Com este contrato, acaba-se por borrar a divisão precisa entre uso público e privado da razão, tornando suas fronteiras difusas (FOUCAULT, 2011). De acordo com Foucault, Kant leva a crer que, ao deixar a liberdade de raciocínio público ampliar-se ao máximo, o entendimento humano acabaria mostrando quão necessária é a obediência. Em outras palavras, o filósofo alemão estabeleceria a premissa segundo a qual "quanto mais liberdade para o pensamento vocês deixarem, mais vocês terão certeza de que o espírito do povo será formado para a obediência" (FOUCAULT, 2011, p. 37).

Se no texto de 1784, Frederico aparece para o filósofo como o agente da Aufklärung, anos depois Kant (1993, p. 102, grifo do autor) transferirá 
esta função a outro fator, a saber, uma "participação segundo o desejo, na fronteira do entusiasmo", expressa pelo povo diante dos acontecimentos referentes à Revolução Francesa de 1789. Ele escreverá a este respeito na obra $O$ conflito das faculdades, de 1798. Nela, coloca-se a questão: "estará o gênero humano em constante progresso para o melhor?" (KANT, 1993, p. 95).

A resposta depende de encontrarmos um fragmento da história da humanidade capaz de evidenciar se ela caminha ou não rumo ao progresso. O que se deve buscar é identificar na experiência certa disposição moral presente nos homens. Logo, "na espécie humana, deve ocorrer qualquer experiência que, enquanto evento, indica uma constituição e aptidão suas para ser causa do progresso para o melhor e (já que tal deve ser o acto de um ser dotado de liberdade) seu autor" (KANT, 1993, p. 100, grifo do autor).

Este evento deve ter "valor de sinal" (FOUCAULT, 2011, p. 17), evidenciando que a causa do progresso humano agiu no passado, tanto quanto age no presente, e agirá no futuro. Porém, alerta-nos Kant (1993, p. 101), este acontecimento buscado não consiste em "acções ou crimes importantes (...) pelos quais o que era grande entre os homens se tornou pequeno, ou o que era pequeno se fez grande". O evento com valor de signo refere-se ao "o modo de pensar dos espectadores" que manifestariam uma "participação universal" diante de determinados fenômenos, revelando "um caráter do gênero humano em seu conjunto" (KANT, 1993, p. 101-102).

Para o filósofo alemão, o signum não consiste na Revolução Francesa em si, mas na simpatia expressa pelo povo diante de alguns acontecimentos que a permearam. O envolvimento dos espectadores, que mesmo não participando da Revolução, demonstraram por ela apreço, é o sinal favorável de uma disposição moral não-contingente para o progresso.

Mas quais seriam os acontecimentos que permearam as convulsões revolucionárias, capazes de atrair a simpatia dos homens? Dirá o filósofo: o interesse deles seria atraído pela possibilidade de criação de uma constituição alinhada à vontade do povo, e pela proteção contra guerras futuras, garantida por esta mesma constituição (KANT, 1993). Conforme Foucault (2011), são estes dois elementos, uma constituição escolhida pelos homens e a possibilidade de afastar a guerra, que permitem a efetivação da Aufklärung, antes assegurada por Frederico II. Neste sentido, "a Revolução é o que remata e continua o próprio processo da Aufklärung" (FOUCAULT, 2011, p. 19).

A mesma fé depositada pelo século XVIII nos poderes emancipadores da razão, não será, contudo, compartilhada pela filosofia dos séculos XIX e XX. A emergência de determinados dispositivos de saber e poder fará surgir no cenário intelectual europeu uma suspeita crescente, expressa pela preocupação com os abusos de autoridade de que a razão ocidental seria responsável. 
Para Foucault (1990), estes dispositivos desenvolveram-se tendo como pano de fundo três acontecimentos históricos. Em primeiro lugar, a elaboração de uma ciência positivista, dotada de profunda confiança em seus métodos e princípios, e também bastante crítica acerca dos resultados que produz. Em segundo, a composição de um Estado que reconhece a si mesmo como "razão e racionalidade profunda da história" (FOUCAULT, 1990, p. 42), valendo-se de medidas de racionalização da economia e da sociedade. Em terceiro lugar, o surgimento, na intersecção entre a ciência positivista e o Estado, de uma ciência estatal ou "estatistmo" (FOUCAULT, 1990, p. 42).

Entre tais acontecimentos, Foucault declara existir uma estreita vinculação, de modo que a ciência assumirá uma importância crescente na composição das forças produtivas, e os poderes estatais lançarão mão de um conjunto de tecnologias cada vez mais refinadas.

A suspeita lançada pela filosofia contemporânea sobre a razão deu-se de maneira distinta na Alemanha e França. No tocante à Alemanha, Foucault associa esta desconfiança ao tradicional pertencimento das Universidades à produção científica e às instancias estatais e administrativas. "Da esquerda hegeliana à Escola de Frankfurt, houve toda uma crítica ao positivismo, ao objetivismo, à racionalização, à technè e à tecnicização" (FOUCAULT, 1990, p. 42).

Uma crítica, de acordo com o filósofo, voltada para "as relações entre o projeto fundamental da ciência e da técnica", procurando explicitar a ligação "entre uma presunção ingênua da ciência (...) e as formas de dominação próprias à sociedade contemporânea" (FOUCAULT, 1990, p. 42). Esta problematização estender-se-á até pensadores não vinculados à esquerda hegeliana, como Husserl, o qual defenderia a existência de uma crise perpassando as ciências europeias na contemporaneidade.

Por sua vez, na França, "a crítica da razão presunçosa e de seus efeitos específicos de poder" (FOUCAULT, 1990, p. 43) assumirá outro destino. Em virtude de diferentes conjunturas políticas e investigações filosóficas, ela se daria no âmbito de um pensamento dito de direita.

Foucault reconhece na Revolução de 1789 e no tímido Iluminismo francês os obstáculos para que se constituísse uma suspeita em torno da racionalidade e do poder. Além disso, o fato de a Reforma religiosa reconhecida pelo filósofo como espaço de desenvolvimento de uma atitude crítica, uma atitude de não ser governado - não ter adquirido na França as mesmas proporções que na Alemanha, resultaria em uma menor ambivalência com relação à razão (FOUCAULT, 1990, p. 43).

Se os denominados philosophes possuíram na França certa importância política, as Luzes, como acontecimento intelectual, foram consideradas "episódio menor" (FOUCAULT, 1990, p. 43) da história da filosofia. Ao contrário, a Alemanha veria nelas "um tipo de manifestação brilhante da destinação profunda da razão ocidental” (FOUCAULT, 1990, 
p. 43). Para filósofos alemães, cumpriria encontrar na Aufklärung as linhas gerais que descrevem a trajetória da racionalidade, colocando a política a ela associada em permanente observação.

Foucault ressalta, porém, uma modificação no tratamento dado pela França às Luzes, a partir do período do pós-guerra. A saber, será "da fenomenologia e dos problemas colocados por ela que nos retorna a questão do que é a Aufklärung" (FOUCAULT, 1990, p. 44). Tais problemas referem-se ao modo de constituição do sentido, a investigação sobre como este pode advir do não-sentido. Em outras palavras, como o surgimento do sentido é possível.

Interrogações desta ordem seriam complementares, de acordo com Foucault, àquela posta na Alemanha: "como se deu que o grande movimento de racionalização nos tenha conduzido a tanto barulho, a tanto furor, a tanto silêncio e tantos mecanismos melancólicos?" (FOUCAULT, 1990, p. 44). Autores franceses argumentarão ser o sentido formulado no interior de "sistemas de coação", por "efeitos de coerção" próprios à "maquinaria significante" (FOUCAULT, 1990, p. 44).

Como resultado, portanto, estabelece-se no debate intelectual do país, a relação entre razão e poder como questão filosófica. Vale destacar, solidarizar-se-á também com este problema a história das ciências, como testemunham seus teóricos mais conhecidos: Cavaillès, Bachelard, Canguilhem.

Foucault vê nas investigações realizadas sobre as relações entre racionalidade e poder o trabalho de abertura de uma pequena fresta, de caráter bastante acadêmico, que permite observar "aquilo que foi, afinal, todo o movimento de fundo de nossa história já há um século" (FOUCAULT, 1990, p. 44).

A crença de as estruturas econômicas e políticas de nossas sociedades serem pouco racionalizadas, o enaltecimento das promessas revolucionárias na primeira metade do século $\mathrm{XX}$, e a convicção na oposição entre "ideologias da violência" e a "verdadeira teoria científica da sociedade, do proletário e da história" (FOUCAULT, 1990, p. 44-45), culminariam em excessos de poder, cujas formas mais radicais o fascismo e o estalinismo encarnariam. Conforme evidencia a análise do biopoder em Foucault (1999b), tais governos totalitários não consistem em uma exceção histórica, mas episódios que multiplicaram e intensificaram dispositivos de saber e poder próprios de nossas democracias.

Impõe-se, assim, para a filosofia contemporânea, novamente a questão formulada por Kant: o que é a Aufklärung? Apropriando-se dela, Foucault interroga sua atualidade, buscando esclarecer as implicações de uma racionalização que afeta, além do "pensamento e a ciência ocidentais desde o século XVI, (...) também as relações sociais, as organizações estatais, as práticas econômicas e talvez até o comportamento dos indivíduos" (FOUCAULT, 1990, p. 45). Trazendo à tona os efeitos não de 
esclarecimento, mas de dominação e assujeitamento de certos aparatos técnicos e políticos, o filósofo poderá tornar acessível ao homem o caminho de saída de sua menoridade.

\section{Referências bibliográficas}

FLORANCE, Maurice. Michel Foucault. In: HUISMAN, Daniel. (Org.). Dicionário dos filósofos. São Paulo: Martins Fontes, 2001.

FOUCAULT, Michel. A psicologia de 1850 a 1950. In: MOTTA, Manoel Barros da. (Org.). Ditos e escritos: problematização do sujeito: psicologia, psiquiatria e psicanálise. Vol. 1. Tradução: Vera Lucia Avellar Ribeiro. Rio de Janeiro: Forense Universitária, 1999a.

A tecnologia política dos indivíduos. In: MOTTA, Manoel Barros da. (Org.). Ditos e escritos: ética, sexualidade, política. Vol. 5. Tradução de Elisa Monteiro e Inês Autran Dourado Barbosa. Rio de janeiro: Forense Universitária, 2004.

A vida: a experiência e a ciência. In: MOTTA, Manoel Barros da. (Org.). Ditos e escritos: arqueologia das ciências e história dos sistemas de pensamento. Vol. 2. 2. ed. Tradução: Elisa Monteiro. Rio de Janeiro: Forense Universitária, 2008a.

. Em defesa da sociedade: curso dado no Collège de France (19751976). Edição estabelecida por: Mauro Bertani e Alessandro Fontana. Direção: François Ewald e Alessandro Fontana. Tradução: Maria Ermantina Galvão. São Paulo: Martins Fontes, 1999b.

. Entrevista a André Berten. Revista de estudos universitários, Sorocaba, v. 36, n. 1, p. 225-235, junho, 2010a.

- História da loucura: na idade clássica. Tradução: José Teixeira Coelho Neto. 7. ed. São Paulo: Perspectiva, 2005.

O governo de si e dos outros: curso dado no Collège de France (1982-1983). Edição estabelecida por: Frédéric Gros. Direção: François Ewald e Alessandro Fontana. Tradução: Eduardo Brandão. São Paulo: Martins Fontes, 2011.

. O que são as Luzes? In: MOTTA, Manoel Barros da. (Org.). Ditos e escritos: arqueologia das ciências e história dos sistemas de pensamento. Vol. 2. 2. ed. Tradução: Elisa Monteiro. Rio de Janeiro: Forense Universitária, 2008b.

. Posfácio de L'impossible prison. In: MOTTA, Manoel Barros da. (Org.). Ditos e escritos: estratégia, poder-saber. Vol. 4. 2. ed. Tradução: Vera Lucia Avellar Ribeiro. Rio de Janeiro: Forense Universitária, $2010 \mathrm{~b}$.

Qu'est-ce que la critique? Critique et Aufklärung. Bulletin de la Societé Française de Philosophie, Paris, ano 84, n. 2, p. 35-63, avril-juin, 1990. 
Une histoire restée muette. In: DEFERT, Daniel; EWALD, François. (Org.). Dits et écrits: 1954-1988. Vol. 1. Colaboração: Jacques Lagrange. Paris: Gallimard, 2001.

. Vigiar e punir: nascimento da prisão. Tradução: Raquel Ramalhete. 26. ed. Petrópolis: Vozes, 2002.

KANT, I. O conflito das faculdades. Tradução: Artur Morão. Lisboa: Edições 70, 1993.

Resposta à pergunta: que é o iluminismo? In: A paz perpétua $e$ outros opúsculos. Tradução: Artur Morão. Lisboa: Edições 70, 2008.

KRAEMER, Celso. Ética e liberdade em Michel Foucault: uma leitura de Kant. São Paulo: EDUC; FAPESP, 2011.

TEMPLE, Giovana Carmo. Aufklärung e a crítica kantiana no pensamento de Foucault. Cadernos de ética e filosofia política, São Paulo, n. 14, p. 225246, jan-jun, 2009.

TORRES FILHO, Rubens Rodrigues. Respondendo à pergunta: quem é a ilustração? Discurso, São Paulo, n. 14, p. 101-102, jan-jun, 1983. 